\title{
Treatment of Hypertension on the Basis of Home Measurements A Case Report
}

\author{
Chinori Kurata, MD; Tadashi Mikami, MD; Akihiko Uehara, MD
}

\begin{abstract}
Should antihypertensive therapy be based on home blood-pressure monitoring in hypertensive patients with marked white-coat phenomenon? A 53-year-old hypertensive woman with marked white-coat phenomenon had been treated on the basis of blood pressure at home without measurements of clinic blood pressure for 5 years. The target of her treatment was changed to clinic blood pressure because of marked electrocardiographic abnormalities, which were subsequently normalized by the treatment given for the office hypertension. Thus, the experience of this case suggests that treatment of cases of hypertension with white-coat phenomenon should not be based only on home recordings. (Jpn Circ J 1998; 62: 858-859)
\end{abstract}

Key Words: Electrocardiography; Hypertension; White-coat phenomenon

$\mathbf{I}$ n some hypertensive patients, blood pressures are much higher in the clinic than at home. Should antihypertensive therapy be based on home blood-pressure monitoring in such patients with marked white-coat phenomenon? Glen et al reported that white-coat hypertension is associated with cardiovascular functional abnormalities! They suggested that such abnormalities can be reversed by antihypertensive treatment. On the other hand, Mejia et al reported that office hypertension was one of factors contributing to resistant hypertension?2 and Mezzetti et al demonstrated that the left ventricular mass index in white-coat resistant hypertensives was significantly lower than in truly resistant hypertensives? They suggested that the use of home or ambulatory blood pressure monitoring could avoid unnecessary overtreatment? ${ }^{2,3}$ Indeed, some physicians tend to treat hypertensive patients with whitecoat phenomenon on the basis of home blood-pressure measurements.

\section{Case Report}

A 53-year-old woman with hypertension was referred by her physician to a cardiologist because of marked electrocardiographic abnormalities (94/7/27; Fig 1), which had not been noticed in 1987. For the 5 years until the consultation, her hypertension had been treated with an angiotensin converting enzyme inhibitor on the basis of home selfmonitoring of blood pressure without measurement of her blood pressure in the office. Her blood pressure at home had been $110-150 / 70-90 \mathrm{mmHg}$. At the time of consultation, her blood pressures at home were $150 \pm 12 / 89 \pm 7$ $($ mean $\pm \mathrm{SD}) \mathrm{mmHg}$ in the morning and $140 \pm 11 / 83 \pm 9$ $\mathrm{mmHg}$ at night, but those in the cardiologist's office were

(Received May 13, 1998; revised manuscript received July 24, 1998; accepted July 28, 1998)

Department of Medicine III, Hamamatsu University School of Medicine, Hamamatsu, Japan

Mailing address: Chinori Kurata, MD, Department of Medicine III, Hamamatsu University School of Medicine, 3600 Handa-cho, Hamamatsu 431-3192, Japan
240-280/140-150 mmHg. She measured her own blood pressure in the upper arm using a semi-automatic oscillometric device. The accuracy of her self-measurements using her device was confirmed by a simultaneous measurement on the other arm in the office with a mercury manometer. The examination of her ocular fundi revealed grade II changes of Keith-Wagener-Barker classification, the cardiothoracic ratio on a chest X-ray film was 58\%, and the echocardiogram showed left ventricular hypertrophy (end-diastolic wall thickness $=14 \mathrm{~mm}$ ). Using several antihypertensive drugs, the cardiologist tried to reduce her blood pressure in his office to lower than $160 / 95 \mathrm{mmHg}$. Her clinic blood pressure was actually reduced to 140-160/ $80-95 \mathrm{mmHg}$ by a combination of doxazosin, atenolol, amlodipine and temocapril, which also lowered her home blood pressures to $100-120 / 60-75 \mathrm{mmHg}$ and gradually reduced the electrocardiographic abnormalities to the normal range (Fig 1). The gradual improvement of the marked electrocardiographic abnormalities by treatment of hypertension with white-coat phenomenon therefore suggests that these abnormalities were associated with hypertensive left ventricular hypertrophy with subendocardial ischemia induced by her severe office hypertension.

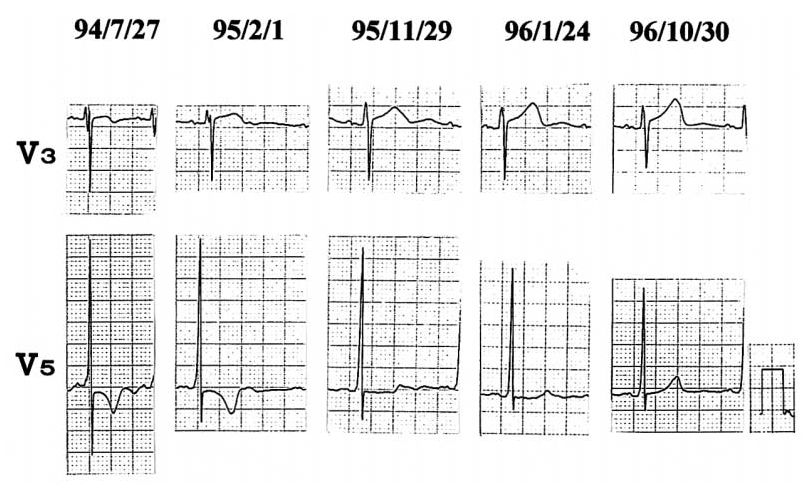

Fig 1. Serial electrocardiograms.

Japanese Circulation Journal Vol.62, November 1998 


\section{Discussion}

Her physician treated her according to the concept that hypertensive patients with white-coat phenomenon should be controlled on the basis of home measurements, 2,3 but her home blood pressure immediately before the consultation was almost always higher than $135 / 85 \mathrm{mmHg}$. Therefore the control of home blood pressures by the physician might be inappropriate, 4,5 although there is no universally agreed upper limit of normal home blood pressure. Moreover, the present case had hypertensive cardiovascular abnormalities such as left ventricular hypertrophy and retinopathy, indicating the necessity to control her blood pressure more strictly, 5 and treating the office hypertension markedly improved the electrocardiographic abnormalities. Recently, it has been demonstrated that a severe white-coat effect is associated with a greater degree of hypertensive complications? Thus, the experience of the present case suggests that treatment of cases of hypertension with white-coat phenomenon should not be based only on home recordings but also on clinic blood pressure, as well as target organ damage?

\section{References}

1. Glen SK, Elliott HL, Curzio JL, LeesKR, Reid JL: White-coat hypertension as a cause of cardiovascular dysfunction. Lancet 1996; 348: $654-657$

2. Mejia AD, Egan BM, Schork NJ, Zweifler AJ: Artefacts in measurement of blood pressure and lack of target organ involvement in the assessment of patients with treatment-resistant hypertension. Ann Intern Med 1990; 112: 270-277

3. Mezzetti A, Pierdomenico SD, Costantini F, Romano F, Bucci A, Di Gioacchino M, et al: White-coat resistant hypertension. Am J Hypertens 1997; 10: 1302-1307

4. Imai Y, Abe K, Hisamichi S, Tsuji I, Satoh H, Nagai K: Evaluation of the effects of antihypertensive medication with home blood pressure measurements in a cohort of northern Japan. Jpn Circ J 1994; 58(Suppl 4): $1324-1327$

5. Joint National Committee: The sixth report of the Joint National Committee on prevention, detection, evaluation, and treatment of high blood pressure. Arch Intern Med 1997; 157: 2413-2446

6. Palatini P, Penzo M, Canali C, Dorigatti F, Pessina AC: Interactive action of the white-coat effect and the blood pressure levels on cardiovascular complications in hypertension. Am J Med 1997; 103: $208-216$ 